\title{
Adjusting White OLEDs with Yellow Light Emission Phosphor Dye and Ultrathin NPB Layer Structure
}

\author{
Jun Wang and Weizhi Li \\ State Key Lab of Electronic Thin Films and Integrated Devices, School of Optoelectronic Information, \\ University of Electronic Science and Technology of China (UESTC), Chengdu 610054, China
}

Correspondence should be addressed to Jun Wang; uestc_wj@yahoo.com

Received 25 January 2013; Revised 1 April 2013; Accepted 15 April 2013

Academic Editor: Shinya Higashimoto

Copyright (C) 2013 J. Wang and W. Li. This is an open access article distributed under the Creative Commons Attribution License, which permits unrestricted use, distribution, and reproduction in any medium, provided the original work is properly cited.

High efficiency white organic light emission devices were demonstrated with phosphor material dye bis[2-(4-tertbutylphenyl)benzothiazolato- $N, C^{2 \prime}$ ]iridium (acetylacetonate) and ultrathin layer structure. The ultra thin layer be composed of $4,4^{\prime}$-bis $[\mathrm{N}$ 1-naphthyl-N-phenyl-amino] biphenyl (NPB) or 4, $4^{\prime}-\mathrm{N}, \mathrm{N}^{\prime}$-dicarbazole-biphenyl : NPB mixed layer with blue light emission. The emission spectra of devices could be adjusted by different phosphor doping concentrations and ultra thin layer structure. Warm white light emitting device could be obtained with $5 \mathrm{wt} \%$ doping concentration and power efficiency of $9.93 \mathrm{~lm} / \mathrm{W}$ at $5 \mathrm{~V}$. Pure white light with Commission Internationale de l'Eclairage (CIE) coordinates of $(0.33,0.30)$ and external quantum efficiency of $4.49 \%$ could be achieved with ultra thin layer device structure and $3 \mathrm{wt} \%$ phosphor doped device.

\section{Introduction}

Organic light-emitting diodes (OLEDs) represent a promising technology for large, flexible, flat-panel displays, and solid state lighting [1-3]. Especially the use of phosphorescent dyes offers a means of achieving high light-emission efficiency, as emission may result from both singlet and triplet states [4]. The application of phosphor has allowed to increase device electroluminescence (EL) external quantum efficiency (QE) up to nearly $20 \%$ photos/carriers equivalent to near $100 \%$ internal quantum efficiency [5]. However, the efficiency of white OLEDs (WOLEDs) is still lower than required in displays or solid-state lighting. Although some phosphorescent OLEDs with green or red light emission have shown very high power efficiency, but high efficient phosphorescent materials with blue light emission were still a deficiency for WOLEDs. Using blue light fluorescent material combining yellow light phosphorescent material to obtain white light is a suitable method, because the rate of blue light in the whole white spectra is much lower than green or red color.

Most of WOLEDs devices were composed of several doping layers. Efficient white OLEDs were reported by Reineke et al. and Cheng et al. with three doped layers in the whole devices structure $[6,7]$, and also some organic devices with white light emission included two doped layers $[8,9]$. Doping process about organic materials with accurate weight rate is uneasy to control. Ultrathin layer instead of doping structure has been reported in some OLEDs in order to decrease the doping difficulty of coevaporating organic materials and improve the stability and reproducibility of the devices [10-12]. Some fluorescent materials have been widely used in ultrathin layer devices, for example, 5,6,11,12-tetraphenylnaphtacene (rubrene) [13] and 4(dicyanomethylene)-2-methyl-6-( $p$-dimethyl aminostyryl)$4 \mathrm{H}$-pyran (DCM) [14]. WOLEDs using a trimeric phenylenvinylene derivative $2,5,2^{\prime}, 5^{\prime}$-tetrakis $\left(4^{\prime}\right.$-biphenylenevinyl)biphenyl (TBVB) as a blue light-emitting layer and ultrathin 5,6,11,12-tetraphenylnaphthacene as a yellow light-emitting layer, shows a maximum luminance of $4025 \mathrm{~cd} / \mathrm{m}^{2}$, current efficiency of $3.2 \mathrm{~cd} / \mathrm{A}$, and Commission Internationale de l'Eclairage $(\mathrm{CIE})$ coordinates of $(0.33,0.34)$ at $4000 \mathrm{~cd} / \mathrm{m}^{2}$ [15]. High efficiency white phosphorescent organic device doped with greenish-blue and red-emitting dye with a power efficiency of $10 \mathrm{~lm} / \mathrm{W}$ at a current density of $0.01 \mathrm{~mA} / \mathrm{cm}^{2}$ and CIE coordinates of $(0.35,0.36)$ has also been achieved [16]. 


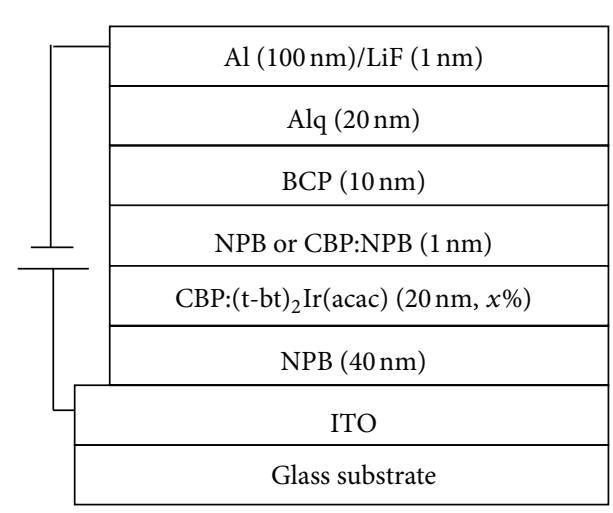

(a)

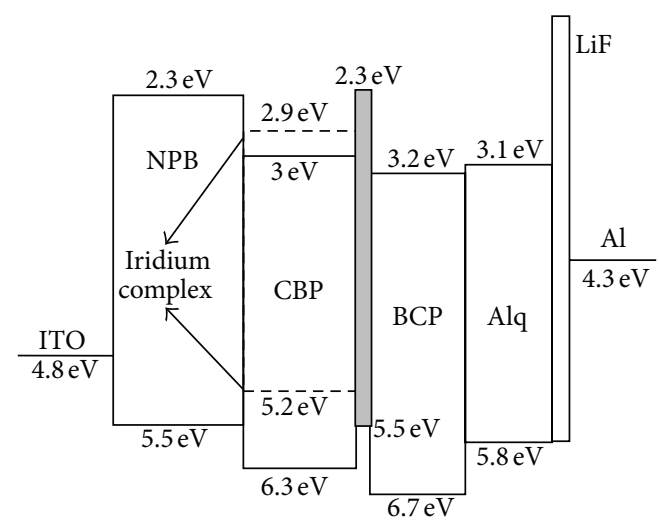

(b)

FIGURE 1: Device structure of organic devices and energy level diagram of relevant materials used in this study. The doping concentration of $(\mathrm{t}-\mathrm{bt})_{2} \operatorname{Ir}(\mathrm{acac})$ was $x \mathrm{wt} \%$ and ultrathin layer was $y$ layer $(1 \mathrm{~nm}), x=3$ for device A and B, $x=5$ for device C and D, $y=\mathrm{CPB}: \mathrm{NPB}(1: 1)$ for device A and C, and $y=\mathrm{NPB}$ for device B and D.

However, ultrathin mixed fluorescent layer with blue light emission emitter was seldom reported as emitter in WOLEDs.

In this work, we demonstrated a WOLEDs using a low ionization potential phosphorescent material bis[2-(4-tertbutylphenyl)benzothiazolato- $N, C^{2 \prime}$ iridium (acetylactonate) $\left[(\mathrm{t}-\mathrm{bt})_{2} \operatorname{Ir}(\mathrm{acac})\right]$ doped in $4,4^{\prime}-\mathrm{N}, \mathrm{N}^{\prime}$-dicarbazole-biphenyl (CBP) as yellow light emission layer and 4,4' -bis[N-1-naphthyl-N-phenyl-amino]biphenyl (NPB) or mixed CBP : NPB as blue light emission layer. The ultrathin blue emission layer could effectively block the transmission of electron and limit the emission zone of devices. High efficiency WOLEDs with blue and yellow lights combined could be obtained with this ultrathin layer structure.

\section{Device Fabrication}

ITO-coated substrate with a sheet resistance of $\sim 15 \Omega / \square$ was ultrasonically cleaned with water, acetone, ethanol, and deionized water for $20 \mathrm{~min}$ each step. Prior to organic layer deposition, ITO-coated glass was treated by oxygen plasma for $2 \mathrm{~min}$ and then loaded into an organic vacuum evaporation chamber with a pressure of $10^{-7}$ Torr. The multilayer organic films were subsequently deposited at a rate of $0.3-$ $1 \AA / s$ without breaking the vacuum. Then, the substrate with organic layers was transported to metal evaporation chamber to evaporate $1 \mathrm{~nm} \mathrm{LiF}$ layer and $100 \mathrm{~nm} \mathrm{Al} \mathrm{cathode.}$

The device structure is ITO/NPB $(40 \mathrm{~nm}) / \mathrm{CBP}:(\mathrm{t}-$ bt ${ }_{2} \operatorname{Ir}(\mathrm{acac})(20 \mathrm{~nm}, x \mathrm{wt} \%) / y$ layer $(1 \mathrm{~nm}) / \mathrm{BCP}(10 \mathrm{~nm}) / \mathrm{Alq}$ $(20 \mathrm{~nm}) / \mathrm{LiF}(1 \mathrm{~nm}) / \mathrm{AL}(100 \mathrm{~nm})(x=3$ for devices $\mathrm{A}$ and $\mathrm{B}$, $x=5$ for devices $\mathrm{C}$ and $\mathrm{D}, y=\mathrm{CPB}: \mathrm{NPB}(1: 1)$ for devices A and $\mathrm{C}$, and $y=\mathrm{NPB}$ for devices $\mathrm{B}$ and $\mathrm{D})$. The layer thickness and deposition rate of organic and inorganic materials were monitored in situ by oscillating quartz thickness monitors. EL spectra and CIE coordinates of the devices were measured with a PR650 spectra colorimeter. The luminance $(L)$ current density $(J)$ bias voltage $(V)$ characteristics were recorded simultaneously with the measurement of EL spectra by combining the spectrometer with a Keithley 2400 programmable voltage-current source. All measurements were performed at room temperature under ambient circumstance.

Figure 1(a) shows the structure of five layer organic device which used tris(8-quinolinolato)aluminum (Alq) as electron transporting layer and 2,9-dimethyl,-4,7-diaphenyl,1,10phenanthroline (BCP) as hole-blocking layer. The phosphor of $(\mathrm{t}-\mathrm{bt})_{2} \operatorname{Ir}(\mathrm{acac})$ was synthesized in our group and doped in CBP as yellow light emitter [17]. The first $40 \mathrm{~nm}$ NPB acted as hole transporting layer and the second thin NPB or CBP : NPB mixed layer was used as blue light emission layer. The energy level diagram of relevant materials used in device was also shown in Figure 1(b).

\section{Experiment Results}

In order to identify the possibility of white light emission combining NPB with blue light emitting and ( $t-b t)_{2} \operatorname{Ir}(a c a c)$ with yellow light emitting, the electroluminescence (EL) spectra of NPB and phosphor dye were tested and shown in Figure 2. The EL spectra of NPB and iridium complex material could be obtained with the device structure of ITO/CuPc/NPB/BCP/Alq/LiF/AL and ITO/NPB/CBP : ( bt ${ }_{2} \operatorname{Ir}(\mathrm{acac}) / \mathrm{BCP} / \mathrm{Alq} / \mathrm{LiF} / \mathrm{AL}$, respectively. From the spectra, the tristimulus values and CIE coordinates of NPB emission were calculated to be $(52.61,53.09,164.05)$ and $(0.195,0.197)$, also these of $(\mathrm{t}-\mathrm{bt})_{2} \operatorname{Ir}(\mathrm{acac})$ dye were $(54.94,55.84,3.99)$ and $(0.479,0.486)$. The CIE coordinates of EL spectra were in good accordance with the test result from PR650 spectra colorimeter. The ideal white emission could be obtained by accurately matching the rate of NPB and (t-bt) ${ }_{2} \operatorname{Ir}(\mathrm{acac})$, which was predicted from CIE 1931 Chromaticity Diagram. And also, some papers have been reported to achieve white OLEDs using NPB as blue light emission materials with different device structures $[18,19]$.

The current density-voltage characteristics of four organic devices were depicted in Figure 3, and the current density increased with the driving voltage increasing and then came to saturation state at near $13 \mathrm{~V}$. It is obvious that the current 


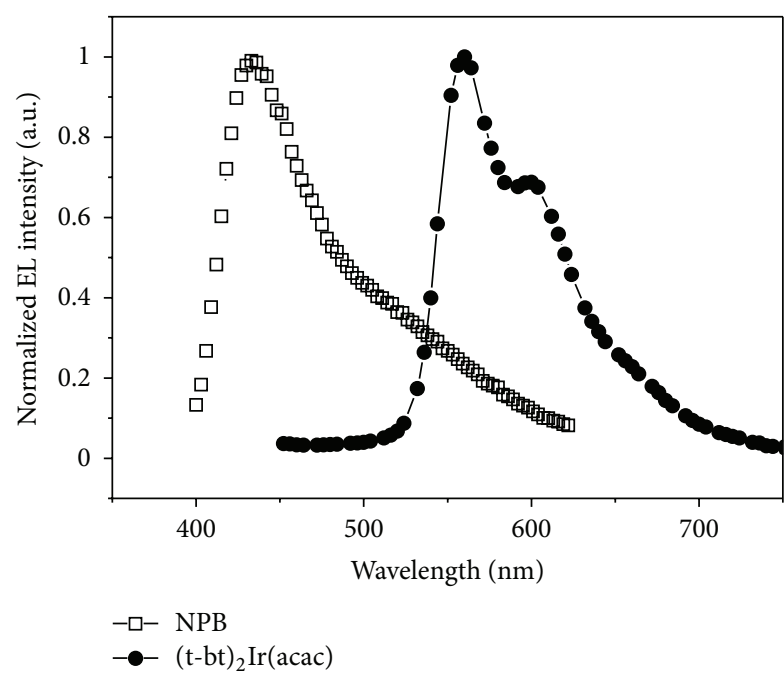

FIgURE 2: Normalized EL spectra of NPB and (t-bt) ${ }_{2} \operatorname{Ir}(\mathrm{acac})$ material, the emission spectra were testing results of organic device structure ITO/CuPc/NPB/BCP/Alq/LiF/AL and ITO/NPB/CBP : (tbt ${ }_{2} \operatorname{Ir}(\mathrm{acac}) / \mathrm{BCP} / \mathrm{Alq} / \mathrm{LiF} / \mathrm{AL}$, respectively.

density of devices with high doping concentration (device C and D) was higher than that with low doping concentration (devices A and B) at the same driving bias, which could be caused by the energy level of different materials. As shown in Figure 1(b), the highest occupied molecular orbital (HOMO) level of $(\mathrm{t}-\mathrm{bt})_{2} \operatorname{Ir}(\mathrm{acac})$ dye was $1.1 \mathrm{eV}$ higher than the CBP host HOMO level of $6.3 \mathrm{eV}$, and the lowest unoccupied molecular orbital (LUMO) level was $0.1 \mathrm{eV}$ higher than the CBP LUMO level of $3.0 \mathrm{eV}$ [20]. The low ionization potential phosphorescent material could promote not only the injection of hole and electron into CBP host, but also the energy transmission from exciton to emitter molecules. So that the current density of device with $5 \%$ dye doped was higher than that of $3 \%$ doped device. To the same doping phosphor device, the current density of device with mixed thin layer was higher than single NPB layer $\left(J_{\mathrm{A}}>J_{\mathrm{B}}, J_{\mathrm{C}}>J_{\mathrm{D}}\right)$. NPB was a typical hole transporting material with very low electronic mobility and electron blocking function. Meanwhile, the LUMO energy level of NPB was $0.7 \mathrm{eV}$ higher than that of $\mathrm{CBP}$, which would set a barrier for the electron transporting. So, the current density of device with mixed thin layer was higher than the pure NPB thin layer at same forward biases. Moreover, the thin NPB layer with $1 \mathrm{~nm}$ thickness could not form an effective blocking layer for electron. The $30 \mathrm{~nm}$ NPB thin film was deposited on the cleaned glass substrate coated with ITO thin film in vacuum evaporation chamber at a pressure of $10^{-7}$ Torr. The surface roughness of NPB film was tested with atomic force microscope SPA-400 and shown in the inset of Figure 5. The peak to valley value of pure $30 \mathrm{~nm}$ NPB film was $5.24 \mathrm{~nm}$ from the atomic force microscope test result. The $1 \mathrm{~nm}$ NPB in those devices acted as blue light emission and very weak electron blocking function.

The voltage versus power efficiency of four devices was also indicated in Figure 3. The $5 \mathrm{wt} \%$ doping concentration devices (devices $\mathrm{C}$ and $\mathrm{D}$ ) showed higher power efficiency

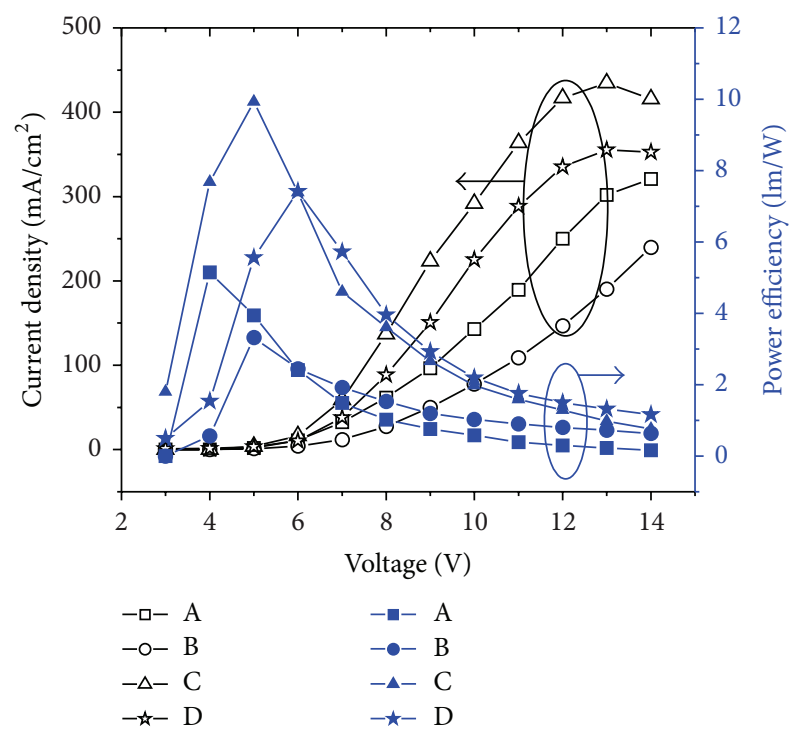

FIGURE 3: The current density-voltage-power efficiency characteristics of four organic devices (device A, B, C and D).

than the $3 \mathrm{wt} \%$ doping concentration ones (devices A and B). There were more phosphorescent molecules in the 5\% doped device, which illustrated more emitting center in CBP host layer. Both singlet and triplet state excitons could be utilized in the emissive process of OLEDs with phosphor material, so that the power efficiency of 5\% doped devices (devices $\mathrm{C}$ and D) were higher than $3 \%$ doping concentration devices. But immoderate phosphor doping concentration would lead to obviously triplet-triplet annihilation phenomena and reduce the power efficiency of phosphor OLEDs. To the same doping concentration device, the maximum power efficiency of device with CBP:NPB mixed thin layer is higher than the pure NPB thin layer device $\left(\eta_{\mathrm{Amax}}>\eta_{\mathrm{B} \max }, \eta_{\mathrm{Cmax}}>\right.$ $\left.\eta_{\text {Dmax }}\right)$. But the efficiency of devices with mixed thin layer dropped down faster than the pure NPB thin layer as shown in Figure 3. In the case of electrophosphorescence device, the long lifetime of emitting triplet excitons could cause the quantum efficiency roll-off phenomena in organic device [21]. When the organic device was at very low current density, the triplet exciton concentration in emission layer was too low to give rise to triplet-triplet fusion, so that the annealing phenomena could be ignored. The triplet exciton concentration increased linearly with the recombination current density. The monomolecular and bimolecular quenching process such as triplet-triplet annihilation or triplet-charge carrier dropped down the device efficiency obviously at high current density [22]. The maximum power efficiency of $9.93 \mathrm{~lm} / \mathrm{W}$ for device $\mathrm{C}$ with the insetting mixed thin layer device structure and $7.42 \mathrm{~lm} / \mathrm{W}$ for device $\mathrm{D}$ with pure NPB thin layer could be achieved.

The luminance-voltage characteristics of four devices and external quantum efficiency (EQE) of device B were shown in Figure 4. The luminance of device increased quickly with the forward bias and achieved maximum value or breakdown at higher voltage. The EQE was an important parameter 


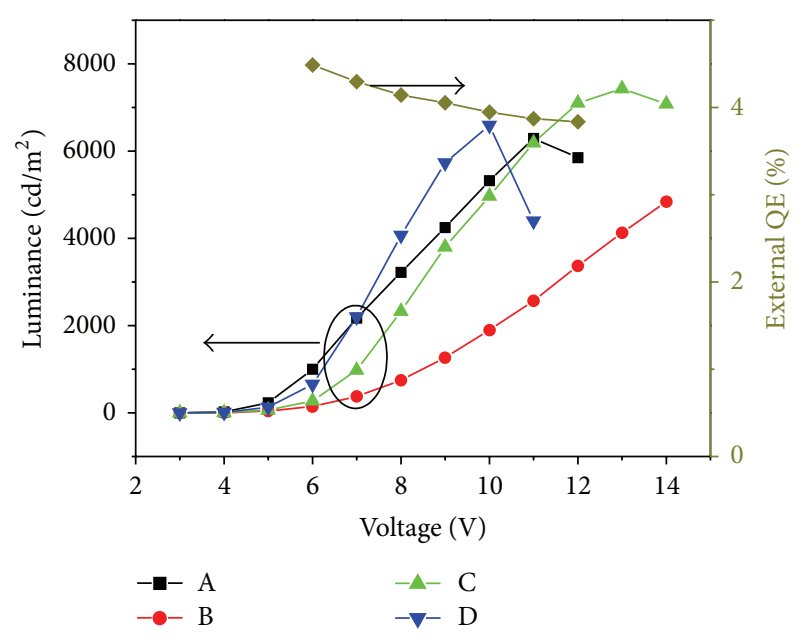

FIGURE 4: The luminance-voltage characteristics of four organic devices External power efficiency of device B was setting in the right bar of figure at different forward biases.

for evaluating the performance of organic device, but it is uneasy to test because of the difficult about collecting and detecting all the photons emitted from a given organic device. Simple method about calculating EQE has been reported with some device characteristics including emission spectra, current density, luminance, and so on [23-25]. The EQE of device $B$ at different voltages was revealed in Figure 4. The EQE value at $6 \mathrm{~V}$ for device B was $4.49 \%$ and dropped down slowly to $3.84 \%$ at $12 \mathrm{~V}$ bias, which was higher than the $3.58 \%$ of device A and $2.29 \%$ of device $\mathrm{C}$ at $12 \mathrm{~V}$ bias. The sequence inconformity between power efficiency and $\mathrm{EQE}$ for the organic devices was caused by the different EL spectra of organic devices.

The white light emission spectrum could be adjusted by the doping concentration of phosphor dye in host material. The emitting spectra of four devices at $12 \mathrm{~V}$ were shown in Figure 5, and those spectra were normalized with the spectrum intensity at $560 \mathrm{~nm}$. The emission peak of (tbt) ${ }_{2} \operatorname{Ir}(\mathrm{acac})$ was $560 \mathrm{~nm}$ with a shoulder peak at $598 \mathrm{~nm}$ and the emission peak of NPB was near $440 \mathrm{~nm}$, which could be identified by the spectra curve shown in Figure 2 and others reports $[18,19]$. If removing the $1 \mathrm{~nm}$ ultrathin layer from the device is done, there would be a very weak emission peak near $440 \mathrm{~nm}$ coming from NPB hole transporting layer, and it could be ignored compared with emission of phosphor dye. The hole was superfluous carriers for most organic devices because that the hole injection and transporting was much easier than electron, so that the emission zone stayed near the hole blocking layer BCP in the four devices. This would promote the emission from ultrathin layer. The spectra of both emissive materials in Figure 5 and current density curve in Figure 3 clearly indicated that the ultrathin layer limited the emission zone of devices and affected the emitting light from devices. From Figure 5, the spectra emitted by phosphor material of four devices were nearly the coincident, but the rate of NPB emission changed observably for different doping concentration and thin layer material devices. Devices A

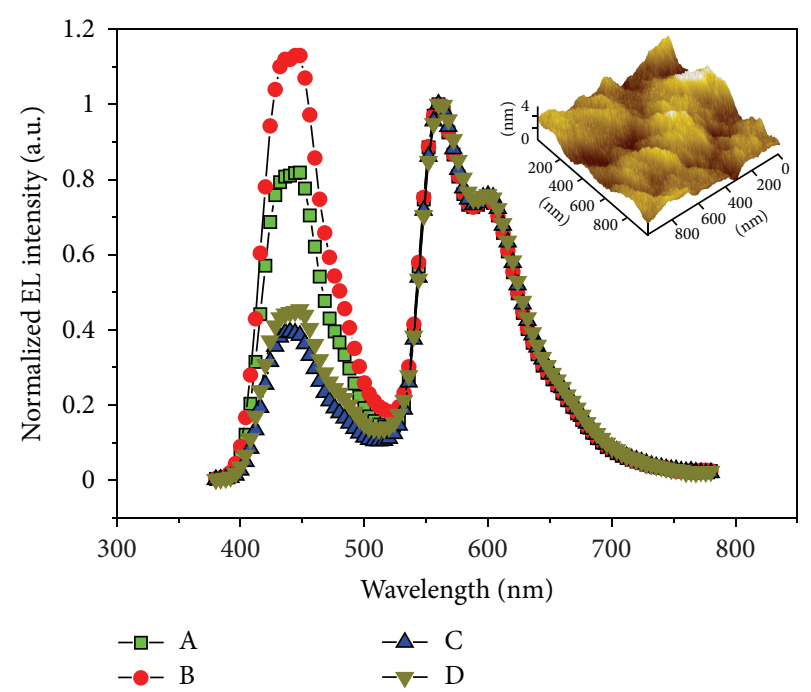

FIgURE 5: Normalized EL spectra of four organic devices at $12 \mathrm{~V}$ bias (normalized with the emission peak at $560 \mathrm{~nm}$, device A: $3 \mathrm{wt} \%$ doping and mixed CPB : NPB thin layer; device B: $3 \mathrm{wt} \%$ doping and pure NPB thin layer; device C: $5 \mathrm{wt} \%$ doping and mixed CPB : NPB thin layer; device D: $5 \mathrm{wt} \%$ doping and pure NPB thin layer). The inset was the AFM testing result of $30 \mathrm{~nm} \mathrm{NPB} \mathrm{film} \mathrm{on} \mathrm{glass}$ substrate.

and $\mathrm{B}$ indicated more suitable emission spectra for pure white OLED, and the high doping concentration devices (devices C and D) showed white-yellow light emitting at $12 \mathrm{~V}$ driving voltage. The spectra could be changed by the doping concentration of phosphor dye in CBP host.

The white light emission spectrum could also be adjusted by ultrathin layer structure. From Figure 5 , in $3 \mathrm{wt} \%$ doped devices (devices A and B), the luminous intensity of NPB emission of device B was stronger than that of device A at $12 \mathrm{~V}$ bias, which was caused by the difference of ultrathin layer material. The component of thin layer structure in device $\mathrm{A}$ was CBP : NPB $(1: 1,1 \mathrm{~nm})$, and that of device $B$ was pure NPB $(1 \mathrm{~nm})$, which indicated that the quantity and probability of $\mathrm{NPB}$ emission in device $\mathrm{B}$ was higher than device $\mathrm{A}$. The same phenomenon occurred in the $5 \mathrm{wt} \%$ doped devices (devices $\mathrm{C}$ and $\mathrm{D}$ ), but the difference about the NPB emission radio was not so obvious. Not only the thin layer structure, but also the electrical properties of thin layer material could affect the emitting characteristics of organic devices. Comparing with the spectra of four organic devices, the $3 \mathrm{wt} \%$ doped devices shown more balance white light in a wide driving bias range than the $5 \mathrm{wt} \%$ doped devices. As an example, the spectra of device B and corresponding CIE coordinates at different biases $(6-12 \mathrm{~V})$ were shown in Figure 6 . The CIE coordinates were located at the white light zone, although it would slightly drop down with the increase of driving voltage. CIE $(0.33$, 0.30 ) was achieved with device $\mathrm{B}$ at $11 \mathrm{~V}$ forward bias. The spectra of device B were not so stable because that the blue light emissive layer was so thin and near to the emissive zone. The probability of blue light emitting from NPB increased at high electronic field intensity and concentration excitons, 
TABLE 1: Some detailed characteristics of four organic devices (different doping concentrations and ultra thin layer structures), including maximum luminance, CIE coordinates, and power efficiency.

\begin{tabular}{lcccc}
\hline Device & $L_{\max }\left(\mathrm{cd} / \mathrm{m}^{2}\right)$ at voltage & $L\left(\mathrm{~cd} / \mathrm{m}^{2}\right)$ at $J=10 \mathrm{~mA} / \mathrm{cm}^{2}$ & CIE $(x, y)$ at voltage & $\eta_{\max }(\operatorname{lm} / \mathrm{W})$ at voltage \\
\hline A & 6290 at $11 \mathrm{~V}$ & 900 & $(0.34,0.30)$ at $11 \mathrm{~V}$ & 5.15 at $4 \mathrm{~V}$ \\
$\mathrm{~B}$ & 5390 at $15 \mathrm{~V}$ & 710 & $(0.33,0.30)$ at $11 \mathrm{~V}$ & 3.32 at $5 \mathrm{~V}$ \\
$\mathrm{C}$ & 7430 at $13 \mathrm{~V}$ & 260 & $(0.40,0.36)$ at $13 \mathrm{~V}$ & 9.93 at $5 \mathrm{~V}$ \\
$\mathrm{D}$ & 6590 at $10 \mathrm{~V}$ & 600 & $(0.39,0.36)$ at $13 \mathrm{~V}$ & 7.42 at $6 \mathrm{~V}$ \\
\hline
\end{tabular}

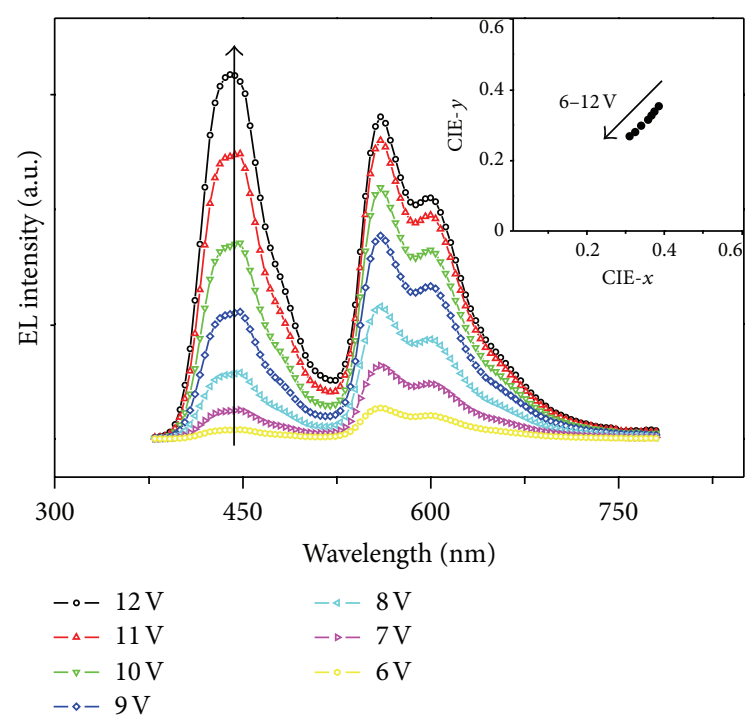

FIGURE 6: Emission spectra of device B at different biases (6-12 V) and the inset was the CIE coordinates $(x$ and $y)$ of corresponding spectra.

which could be found in some other white light emission devices [26, 27].

In order to analyze the differences of four devices, some other characteristics of four devices such as maximum power efficiency, maximum luminance, luminance at certain current density, CIE coordinate, maximum efficiency were shown in Table 1. The maximum power efficiencies of device $\mathrm{B}(3.32 \mathrm{~lm} / \mathrm{W})$ and device $\mathrm{D}(7.42 \mathrm{~lm} / \mathrm{W})$ were lower than device A $(5.15 \mathrm{~lm} / \mathrm{W})$ and device C $(9.93 \mathrm{~lm} / \mathrm{W})$, respectively. Warm white light $(\mathrm{CIE}(0.40,0.36))$ could be obtained in device $\mathrm{C}$ with high power efficiency, and pure white light [CIE $(0.34,0.30)]$ could be achieved in device A with maximum power efficiency of $5.15 \mathrm{~lm} / \mathrm{W}$ at $4 \mathrm{~V}$. There was obvious CIE coordinates shift between $3 \mathrm{wt} \%$ and $5 \mathrm{wt} \%$ doped devices, which was in accordance with the device spectra shown in Figure 5. The energy level of (t-bt) ${ }_{2} \operatorname{Ir}(\mathrm{acac})$ caused it more suitable to accept the energy transmission from excitons than $\mathrm{NPB}$, so that more phosphor dye participated in the emitting process instead of NPB in high doping concentration device. If increasing the doping concentration to $8 \mathrm{wt} \%$ is done, high efficiency yellow light emission device could obtained, but it is hard to get a balanced white light spectra with the NPB ultrathin layer structure.

\section{Conclusion}

In summary, high efficiency WOLEDs using ( $t-b t)_{2} \operatorname{Ir}(a c a c)$ doped in CBP as yellow light emission layer and pure NPB or mixed CBP : NPB ultrathin layer as blue light emission layer were demonstrated in this paper. The nondoped ultrathin blue emission layer could effectively block the transmission of electron and limit the emission zone of devices. The spectra, power efficiency, CIE coordinate could be adjusted by changing the doping concentration of phosphor dye or the material of thin layer structure. Warm white light with $9.93 \mathrm{~lm} / \mathrm{W}$ power efficiency and $\operatorname{CIE}(0.39,0.36)$, and pure white light with $4.49 \%$ external QE and CIE $(0.33,0.30)$ could be obtained with ultrathin layer device structure. Further efficiency bright white OLEDs can be anticipated using the ultrathin layer device structure with high efficiency blue light emission material.

\section{Acknowledgments}

This work is partially supported by National Science Foundation of China (NSFC) via Grant no. 61006036. One of the authors (Jun Wang) thanks "the Fundamental Research Funds for the Central Universities" (ZYGX2011X012) and Program for New Century Excellent Talents in University (NCET-10-0299) for financial support.

\section{References}

[1] M. C. Gather, K. Anne, and M. Klaus, "White organic lightemitting diodes," Advanced Materials, vol. 23, no. 2, pp. 233-248, 2011.

[2] T. H. Han, Y. Lee, M. Choi et al., "Extremely efficient flexible organic light-emitting diodes with modified graphene anode," Nature Photonics, vol. 6, pp. 105-110, 2012.

[3] L. Zhou, H. Zhang, W. Shi et al., "Mechanisms of efficiency enhancement in the doped electroluminescent devices based on a europium complex," Journal of Applied Physics, vol. 104, no. 11, Article ID 114507, 2008.

[4] K. S. Hyun, J. Jang, Y. K. Soo, and J. Y. Lee, "Origin of colour stability in blue/orange/blue stacked phosphorescent white organic light-emitting diodes," Journal of Physics D, vol. 42, no. 1, Article ID 015104, 2009.

[5] H. Uoyama, K. Goushi, K. Shizu, H. Nomura, and C. Adachi, "Highly efficient organic light-emitting diodes from delayed fluorescence," Nature, vol. 492, pp. 234-238, 2012.

[6] S. Reineke, F. Lindner, G. Schwartz et al., "White organic lightemitting diodes with fluorescent tube efficiency," Nature, vol. 459, no. 7244, pp. 234-238, 2009. 
[7] G. Cheng, T. Fei, Y. Zhao, Y. Cheng, Y. Ma, and S. Liu, "Highly efficient white organic light-emitting devices based on a multiple-emissive-layer structure," Thin Solid Films, vol. 516, no. 15, pp. 5133-5136, 2008.

[8] S. L. Lai, S. L. Tao, M. Y. Chan et al., "Efficient white organic light-emitting devices based on phosphorescent iridium complexes," Organic Electronics, vol. 11, no. 9, pp. 1511-1515, 2010.

[9] T. Han, Y. Lee, M. R. Choi et al., "Extremely efficient flexible organic light-emitting diodes with modified graphene anode," Nature Photonics, vol. 6, pp. 105-110, 2012.

[10] Y. Zhao, J. Chen, and D. Ma, "Realization of high efficiency orange and white organic light emitting diodes by introducing an ultra-thin undoped orange emitting layer," Applied Physics Letters, vol. 99, Article ID 163303, 2011.

[11] W. Wen, J. Yu, L. Li, J. Wang, and Y. Jiang, "Steady full colour white organic light-emitting devices consisting of an ultrathin red fluorescent layer," Journal of Physics D, vol. 42, no. 1, Article ID 015107, 2009.

[12] D. Yan, J. Lu, M. Wei et al., "Heterogeneous transparent ultrathin films with tunable-color luminescence based on the assembly of photoactive organic molecules and layered double hydroxides," Advanced Functional Materials, vol. 21, no. 13, pp. 2497-2505, 2011.

[13] Y. M. Shi, Z. B. Deng, D. H. Xu, Z. Chen, and X. F. Li, "Quantum well organic light emitting diodes with ultra thin Rubrene layer," Displays, vol. 28, no. 2, pp. 97-100, 2007.

[14] G. Cheng, Z. Xie, Y. Zhang, Y. Ma, and S. Liu, "Blue and white organic light-emitting devices using 2,5-diphenyl -1, 4distyrylbenzene with two trans-double bonds as a blue emitting layer," Materials Science Forum, vol. 475-479, no. 3, pp. 18051808, 2005.

[15] G. Cheng, Y. Zha, Y. Zhang et al., "White organic light-emitting devices using 2,5,2',5'-tetrakis(4'-biphenylenevinyl)-biphenyl as blue light-emitting layer," Applied Physics Letters, vol. 84, no. 22, pp. 4457-4459, 2004.

[16] S. J. Lee, J. H. Seo, J. H. Kim et al., "Efficient triplet exciton confinement of white organic light-emitting diodes using a heavily doped phosphorescent blue emitter," Thin Solid Films, vol. 518, no. 22, pp. 6184-6187, 2010.

[17] J. Wang, J. Yu, H. Lin, X. Wei, and Y. Jiang, "Efficient small molecular and polymer organic devices using bis[2-(4-tertbutylphenyl)benzothiazolato-N,C2' ] iridium (III) (acetylacetonate) dye as emitter," Journal of Luminescence, vol. 128, no. 9, pp. 1379-1383, 2008.

[18] L. Zhou, J. Tang, Z. Guo et al., "Bright electroluminescent devices with tunable spectra obtained by strictly controlling the doping concentration of electron injection sensitizer," Journal of Luminescence, vol. 130, no. 11, pp. 2265-2270, 2010.

[19] L. Zhou, X. Li, X. Li, J. Feng, S. Song, and H. Zhang, "Highbrightness, broad-spectrum white organic electroluminescent device obtained by designing light-emitting layers as also carrier transport layers," Journal of Physical Chemistry C, vol. 114, no. 49, pp. 21723-21727, 2010.

[20] J. Wang, Y. D. Jiang, J. S. Yu, S. L. Lou, and H. Lin, "Low operating voltage bright organic light-emitting diode using iridium complex doped in 4, 4'-bis [N-1-napthyl-N-phenylamino]biphenyl," Applied Physics Letters, vol. 91, no. 13, Article ID 131105, 2007.

[21] S. Reineke, K. Walzer, and K. Leo, "Triplet-exciton quenching in organic phosphorescent light-emitting diodes with Ir-based emitters," Physical Review B, vol. 75, no. 12, Article ID 125328, 2007.
[22] A. P. Monkman, "Singlet generation from triplet excitons in fluorescent organic light-emitting diodes," ISRN Materials Science, vol. 2013, Article ID 670130, 19 pages, 2013.

[23] M. Furno, T. C. Rosenow, M. C. Gather, B. Lüssem, and K. Leo, "Analysis of the external and internal quantum efficiency of multi-emitter, white organic light emitting diodes," Applied Physics Letters, vol. 101, Article ID 143304, 2012.

[24] M. Furno, R. Meerheim, S. Hofmann, B. Lüssem, and K. Leo, "Efficiency and rate of spontaneous emission in organic electroluminescent devices," Physical Review B, vol. 85, Article ID 115205, 2012.

[25] M. Shukla and N. Brahme, "Analytical measurements for quantum efficiency of organic light emitting diodes," Journal of International Academy of Physical Sciences, vol. 15, pp. 231-238, 2011.

[26] Q. Wang, J. Ding, M. Dongge et al., "Harvesting excitons via two parallel channels for efficient white organic LEDs with nearly $100 \%$ internal quantum efficiency: fabrication and emissionmechanism analysis," Advanced Functional Materials, vol. 19, no. 1, pp. 84-95, 2009.

[27] Y. Zhao, L. Zhu, J. Chen, and D. Ma, "Improving color stability of blue/orange complementary white OLEDs by using single-host double-emissive layer structure: comprehensive experimental investigation into the device working mechanism," Organic Electronics, vol. 13, pp. 1340-1348, 2012. 

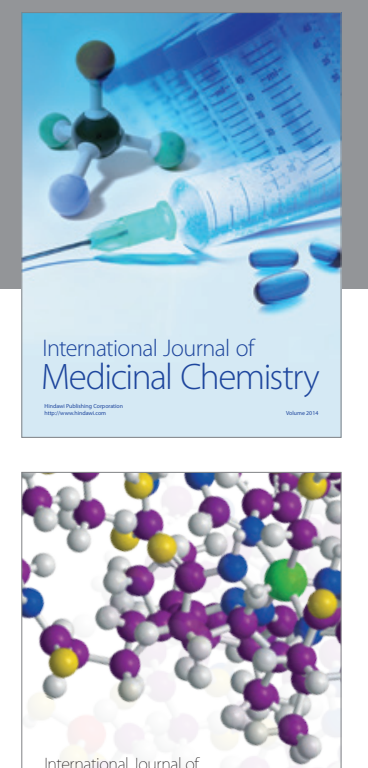

\section{Carbohydrate} Chemistry

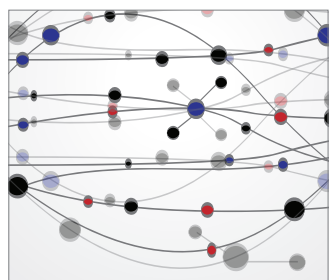

The Scientific World Journal
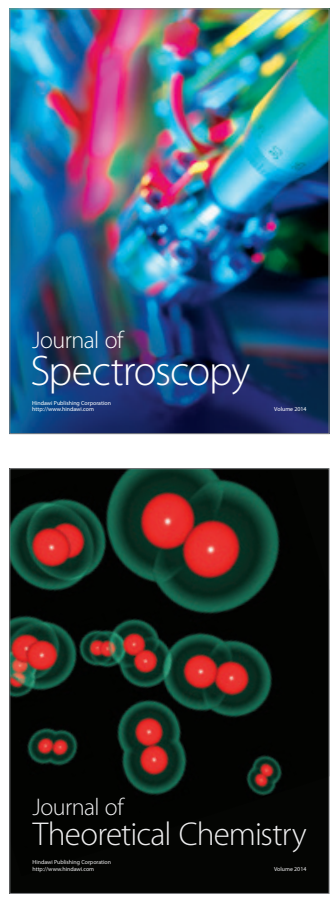
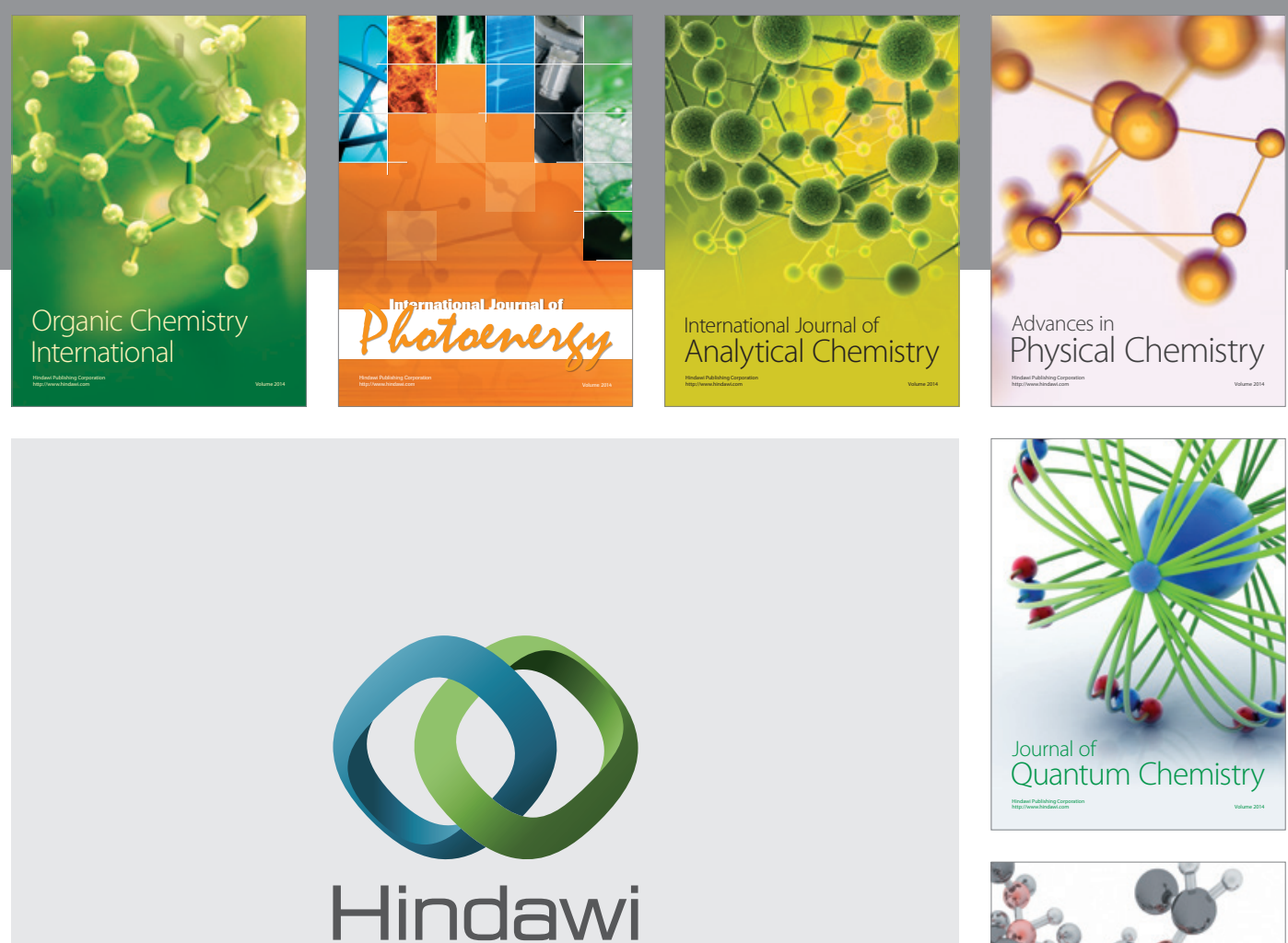

Submit your manuscripts at

http://www.hindawi.com

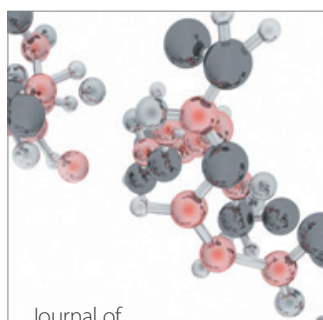

Analytical Methods

in Chemistry

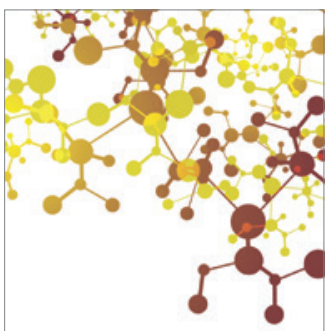

Journal of

Applied Chemistry

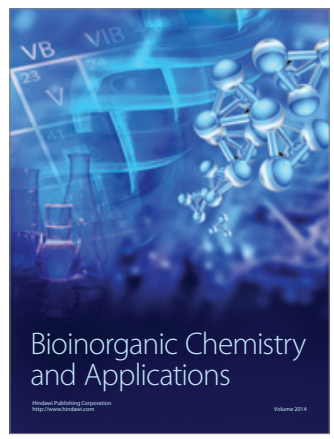

Inorganic Chemistry
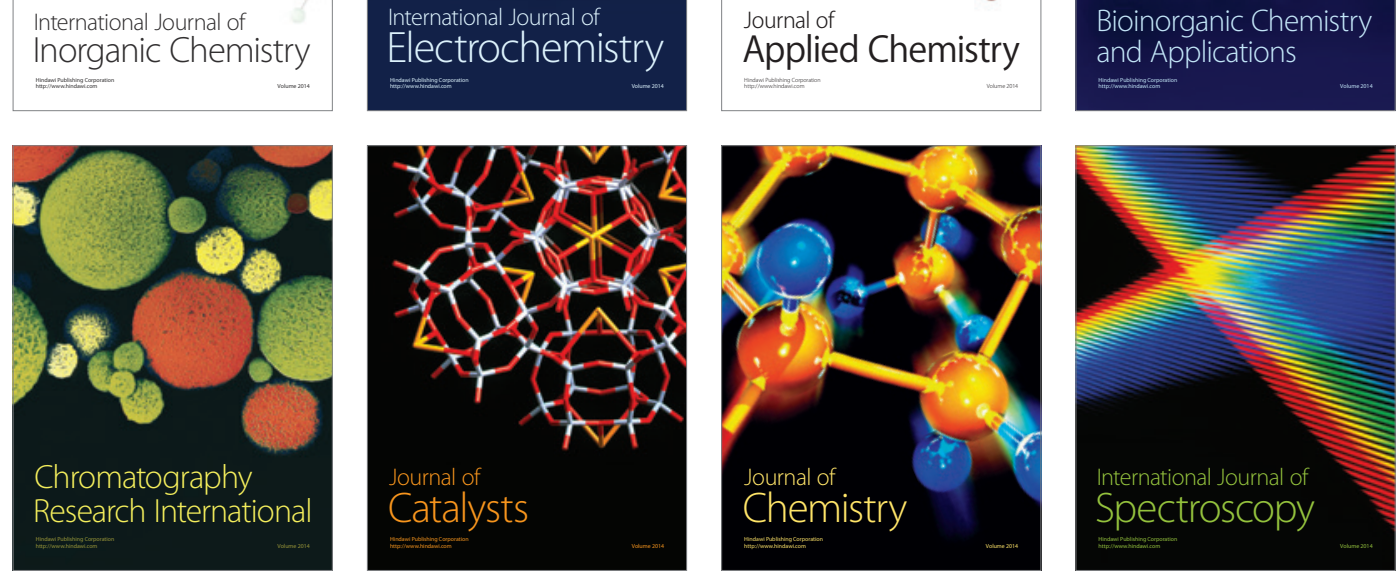